for the farmer. The service is staffed by those who have had postgraduate or graduate training. While all members of the staff have had some training in animal nutrition, at each Provincial Headquarters (England and Wales) or University Centre (Scotland) there is a specialist Nutrition Officer who gives on special problems of nutrition advice that is of too advanced a nature for the local unspecialized advisory officer. Such specialized officers are in touch with the Research Institutes and receive information on current research problems both in this country and abroad from the publications of the Commonwealth Bureau of Animal Nutrition at Aberdeen. It is the duty of the Bureau to abstract all research literature on animal nutrition and to publish the abstracts and review articles periodically.

Not only does the National Agricultural Advisory Service deal with queries from farmers, but it also spreads the newer knowledge in animal nutrition to the farmers by arranging lectures at suitable times and places.

Under the direction of the Agricultural Improvement Council of the Ministry of Agriculture an attempt is made to extend the findings of research into agricultural practice at various Husbandry Farms throughout the country. For example, at a farm at Trawscoed near Aberystwyth young heifers are being reared on high and low planes of nutrition, to determine what will be the effects on the partition of nutrients between growth and milk production at different stages of life. Experiments with antibiotics in pig feeding are being made on some of these farms also. Visits of farmers to see such practical experiments in progress stimulate them to study the results of nutritional research and show them how best the results can be put into practice.

In addition to these organizations for teaching and research, more or less Government sponsored, much work on education in animal nutrition is carried out by large feeding-stuffs manufacturers, who have their own nutrition experts. These are often given refresher courses at Agricultural Colleges. Such firms also have their own experimental farms and pioneer new developments among the farmers. For example, one of them has for the last few years run a litter testing station for pigs, where the strains that have the power of converting feeding-stuffs into meat most efficiently are picked out and used as breeding stock.

REFERENCE

Woodman, H. E. (1952). Bull. Minist. Agric., Lond., no. 48.

\title{
Nutritional Education in the Army
}

\section{By Freda S. Leben, Army Medical Directorate, The War Office,} London, S.W.I

Efficient nutrition in the Army is of great importance for three reasons. It helps maintain good health amongst the troops; it helps keep up the standard of physical efficiency the army requires; it helps maintain morale. 
The type of nutrition education provided in the army is of an essentially practical nature. Roughly speaking there are four levels at which nutrition is taught: to medical officers and nursing officers, to officers and men of the Army Catering Corps; to specialist other ranks of the R.A.M.C. and Q.A.R.A.N.C. of various categories, such as nursing orderlies and hygiene assistants; to regimental officers and other ranks.

\section{The Royal Army Medical College}

The College organizes courses mainly for various medical officers, and nutrition is included in all the courses. Short introductory courses are given to national service medical officers on entry into the army, and longer instruction is given to regular medical officers after about to years of service. Both these courses include two lectures on nutrition, which cover much ground in a short time. The emphasis of these lectures is on the calorie requirements of the soldier and on demonstrating how to draw up a ration scale. During the conduct of his work an army medical officer may wish to amend existing ration scales and must be able to put up a good nutritional, as well as medical, argument for doing so. Food hygiene is dealt with in separate lectures.

Army medical officers who have taken their Diploma of Public Health receive at the College a 2-month course in which Public Health problems as applied to army life are discussed. A ration scale is provided and comments on the adequacy and suitability have to be prepared by the students as an exercise. Officers who have taken their Diploma in Tropical Medicine and Hygiene receive two lectures on nutrition, one general and similar to that taken by the D.P.H. graduates and the other on nutrition surveys. Participation in nutrition surveys is sometimes required of army medical officers on service overseas.

A special course is given for officers of the Royal Army Service Corps, whose duties include the handling of the army food supplies. They are given two lectures on nutrition, one on the basic principles and the other on medical aspects of the ration scale.

All medical officers attending courses at the College are provided with a set of notes on nutrition, which are continually brought up to date. They contain basic information on nutritional principles, as well as information relevant to nutrition in the army, e.g. nutritive value of various army ration scales.

The College museum includes a nutrition exhibit illustrating the principles of a balanced diet and how to apply them in the army. Exhibits of various army ration packs are included. From time to time an Army Health specialist on a course may be selected to reorganize and bring up to date the nutrition section of the museum as part of his training.

\section{The Army Catering Corps}

The tuition given in the Army Catering Corps is largely practical and in applied nutrition. Those receiving instruction in Army Catering Corps training establishments can be classified as officers, regular soldiers, apprentice chefs or national servicemen. 
Officers. There are three types of courses for officers : regular officers take a 3-year course including I2 months' training in the civilian catering industry, National Service commissioned officers undergo 6 months' training in army catering, Regimental Messing Officers take a course designed to acquaint them with the functions of army messing.

National Servicemen, regular soldiers, hospital and unit cooks. Personnel come into the Army Catering Corps with or without previous catering experience in civilian life. Regulars receive a 16 -week and National Servicemen a I2-week basic cookery training, and this is apart from their military training. Men who have attended a recognized catering course at a civilian technical school are given a modified course initially and subsequently are selected for advanced training. A unit cook is instructed in the use of field apparatus during his basic training, and the hospital cook receives more instruction in dietary and invalid cookery.

Unit cooks during their basic training learn little of the theory of nutrition, but hospital cooks get in place of field work the minimum possible instruction in basic dietetics and carry out practical work in Military Hospitals to round off their training. The nutrition theory taught during basic training is very elementary and confined to hospital messing, and the invalid cookery included is entirely confined to preparing suitable dishes.

In the main, cooks are initially classified as Group B Class 3 unit or hospital cook. Unit cooks with civilian experience and of a high standard can be trade tested as tradesmen Group B Class 2 unit cook after a 2-week additional training. Hospital cooks must spend 3 months in a hospital before they can be upgraded to Group $B$ Class 2 cooks.

All cooks after having had experience of cooking in units and hospitals may, if recommended, attend advanced courses for Group B Class I and subsequently Group A Class I, which are of 8 and Io weeks' duration, respectively. These courses include training in advanced cookery, kitchen administration, elementary nutrition, food hygiene and various types of diet used in military hospitals.

Trade tests in these categories can be favourably compared with City and Guilds of London examinations in cookery nos. ${ }_{5} 5^{1}$ and $1_{5} 2$. Corporals and above attend special courses to qualify them as N.C.O's.

Apprentice chefs. Enlisted boys between the ages of $\mathrm{I}_{4} \frac{1}{2}$ and $\mathrm{I}_{5} \frac{1}{2}$ are accepted for training as apprentice chefs after passing the entrance examination for army boys, apprentice class. They are given a 3 -year course of the same kind as the training given to students in the Catering Industry or Technical Colleges.

Thus most of the nutrition education given in the Army Catering Corps is of an applied and practical nature. All officers and cooks in the army specializing in hospital work are given the minimum basic instruction in nutrition.

The planned Army ration scales in the U.K. and overseas must be approved by the Medical Branch of the War Office, so that the food when prepared and cooked by the Army Catering Corps uses all the entitlements to provide balanced meals for the soldier's requirements. 


\section{The Army School of Health}

Courses of practical instruction in the maintenance of the health of the soldier are given to various groups-medical officers, regimental officers and other ranks and hygiene assistants.

Medical officers attending courses at the School receive some nutrition teaching, which supplements what will have been given previously at the Royal Army Medical College.

Regimental officers receive a lecture on a balanced diet in their course, as their duties in a unit may include those of a messing officer. In addition, messing officers during their training in the Army Catering Corps visit the School of Health and receive some instruction in nutrition and food hygiene.

Men of the R.A.M.C. wishing to qualify as hygiene assistants receive instruction at the School, and there are three grades of proficiency they are able to attain. By the time a man has attained his third or Class I certificate he is of a status approximately equivalent to that of a civilian sanitary inspector.

These men receive three lectures on nutrition in each of the three class courses. The first lecture covers the basic principles of nutrition. The second lecture is a discussion of the Army ration scales, including a visual demonstration of the Home Services Ration Scale, which gives the men a good idea of the quantities available. Ration packs are also shown. In the lecture the calorie values of the various rations are related to the energy requirements of the soldier in varying circumstances and climates. The third lecture deals with deficiency diseases; discussion of them is of importance to the soldier, who may meet them in his service overseas. Further lectures on nutrition, more detailed and of a higher standard, are given in the Class 2 and Class I courses. Questions on nutrition are included in the examination papers.

Film strips and films on nutrition, too, are used to illustrate lectures. Any visual aids that are used in teaching nutrition to the soldier are brought as far as possible to the level of his interest and applied to the conditions he will meet. The cookhouse attached to the School is used in all the courses to demonstrate practical problems of nutrition such as correct vegetable storage, keeping of left-overs and in particular demonstration of food hygiene. Food hygiene is given importance in these courses and plays an enormous part in maintaining army health. Based on the School is a Mobile Health Unit, which tours the country, spending from 6 to 8 weeks in a command. The unit has models for demonstrations and films, some on nutrition. Displays and lectures are given to regular and territorial units.

\section{Nursing personnel}

Nursing orderlies of the R.A.M.C. and Q.A.R.A.N.C. receive their instruction from sister tutors and medical officers at the R.A.M.C. depot and Q.A.R.A.N.C. depot and at the various military hospitals in which they serve after their preliminary depot training. The subjects taught include nutritional principles and their application to the feeding of invalids. 


\section{Publications}

Several publications issued by the War Office have reference to nutrition.

I. 'Your Health and You'. This is a small booklet issued to every soldier. Very simple nutrition is discussed in various paragraphs, with particular reference to the importance of consuming the whole of the ration scales provided and advice about the consumption of certain local foods when overseas.

2. 'Notes for the Preservation of the Health of Women and Children proceeding to 'Tropical Countries'. This is a booklet issued to the families of soldiers proceeding overseas. It contains hints on infant feeding on board a troopship and at stations overseas. Valuable advice on the use of fresh fruit and vegetables overseas, and on the efficient organization of the kitchen, food storage and disposal of waste in a families' quarters overseas, is also given.

3. 'The Handbook of Army Health'. This publication is distributed to all units and includes a chapter on Food and Health. The basic principles of nutrition are discussed, particularly in relation to the energy requirements of the soldier while doing various jobs. There are also notes on the storage, preparation, cooking and serving of food.

4. R.A.M.C. Training Pamphlet No. 3. This manual is one of the books used in training nursing orderlies. A section deals with food and cookery and covers the principles of nutrition and the management of an invalid dietary.

5. 'The Manual of Army Health'. This is for distribution to medical officers; it has recently been rewritten and is not yet published. The book has a large section on nutrition with detailed information.

6. Manual of Army Catering. The A.C.C. have compiled a very comprehensive manual, recently rewritten and about to be published, which includes excellent material on recipes, on improvization in catering in the field and on equipment, and several chapters on elementary nutrition and therapeutic dietetics.

7. Catering Circular. This is a small journal produced quarterly for the A.C.C.; it contains useful articles of current information on subjects such as food hygiene, dehydrated foods and nutritional principles behind menu planning. It is available to all units.

The army is aware of the importance of good feeding and good nutrition in helping to keep up the standard of physique of the soldier. From a random sample of the medical records of 166 National Servicemen serving in $195^{2}$, the following information about their gains in weight was obtained.

On the average, in 7 weeks before call-up there was a gain of $6 \mathrm{oz}$. in weight. In I I weeks after call up there was a gain of $46 \mathrm{oz}$., that is, almost five times what might be called the natural rate of gain. It is probable that after this initial period the weight changes are normal for men at that age. Good nutrition is achieved in the 
army by combining the provision of good feeding with teaching the principles of nutrition, in the way that they apply to the soldier, to the men who will be responsible for their practical application.

\section{The Place of Nutrition in the Institutional Management Association Certificate Course}

By Agatha Lumby, Institutional Management Association, 324 Gray's Inn Road, London, W.C.2

\section{The scope of institutional management}

Institutional management involves the responsibility for all the domestic side of any large undertaking, and training for it includes both theoretical and practical work. The syllabus embraces everything connected with the building and its care, equipment and contents, as well as the organization of staff and household work, and also cooking, catering and nutrition, business affairs and book-keeping, with some study of the science subjects connecting these matters.

There are five principal lines of work for which the course provides a basic training; they include the management of the household arrangements in schools and colleges, the catering and domestic management in hospitals, catering management in industrial canteens, hotel and restaurant management and the organization of the School Meals Service. Catering has therefore to be considered in relation to the nutritional requirements of young children, students, heavy and light industrial workers and men and women in sickness and in health, as well as those on pleasure bent. In a training that covers so wide a field, nutrition is only one of several important subjects in a very full syllabus.

The training for institutional management covers 2 years in a College and $I$ year taken in employment. During the 2 years in College, the syllabus assumes $1000 \mathrm{~h}$ of instruction each year. As the examining body the Institutional Management Association does not dictate to any College how it should arrange its syllabus. A rough estimate of the proportion of time to be devoted to each subject is available, however, as a guide to anyone seeking advice on the matter.

The suggested percentages of time are cookery and catering, 45; nutrition, physiology and hygiene, $\mathrm{x}_{5}$; business management, accounts, book-keeping and English, $\mathrm{r}_{5}$; institutional organization and methods of cleaning, 25.

A large proportion of training time is of necessity spent on practical work, both on acquiring practical skill and in gaining practical experience on the job. One of the foundations of a happy household, whether large or small, is good cooking; unless the person managing the household side of any institution, be it school, college, hospital, canteen or hotel, is herself fully conversant with practical cookery and kitchen management, no amount of theoretical knowledge can compensate. The suggested time allotted to cooking, catering and nutrition is $5 \mathrm{I} \%$, and of that 